\title{
Development of Antibody-Coated Magnetite Nanoparticles for Biomarker Immobilization
}

\author{
Christian Chapa Gonzalez, Carlos A. Martínez Pérez, \\ Alejandro Martínez Martínez, Imelda Olivas Armendáriz, Oscar Zavala Tapia, \\ Adriana Martel-Estrada, and Perla E. García-Casillas
}

Universidad Autónoma de Ciudad Juárez, Instituto de Ingeniería y Tecnología, Avenida del Charro 610 Norte, Colonia Partido Romero, 32315 Ciudad Juárez, CHIH, Mexico

Correspondence should be addressed to Perla E. García-Casillas; perlaelviagarcia@yahoo.com

Received 2 September 2013; Accepted 21 January 2014; Published 26 March 2014

Academic Editor: Chih-Hung Hsiao

Copyright (C) 2014 Christian Chapa Gonzalez et al. This is an open access article distributed under the Creative Commons Attribution License, which permits unrestricted use, distribution, and reproduction in any medium, provided the original work is properly cited.

\begin{abstract}
Magnetic nanoparticles (MNPs) have great potential in biomedical applications because of their magnetic response offers the possibility to direct them to specific areas and target biological entities. Magnetic separation of biomolecules is one of the most important applications of MNPs because their versatility in detecting cancer biomarkers. However, the effectiveness of this method depends on many factors, including the type of functionalization onto MNPs. Therefore, in this study, magnetite nanoparticles have been developed in order to separate the $5^{\prime}$-nucleotidase enzyme (5eNT). The $5 \mathrm{eNT}$ is used as a bio-indicator for diagnosing diseases such as hepatic ischaemia, liver tumor, and hepatotoxic drugs damage. Magnetic nanoparticles were covered in a core/shell type with silica, aminosilane, and a double shell of silica-aminosilane. A ScFv (fragment antibody) and anti-CD73 antibody were attached to the coated nanoparticles in order to separate the enzyme. The magnetic separation of this enzyme with fragment antibody was found to be $28 \%$ higher than anti-CD73 antibody and the enzyme adsorption was improved with the double shell due to the increased length of the polymeric chain. Magnetite nanoparticles with a double shell (silica-aminosilane) were also found to be more sensitive than magnetite with a single shell in the detection of biomarkers.
\end{abstract}

\section{Introduction}

Nanomedicine is generally defined as the biomedical application of nanotechnology. Nanomagnetism is at the forefront of the nanosciences as magnetic nanomaterials are the most promising materials used in the clinical diagnosis and in various therapeutic applications $[1,2]$. Magnetic particles have special features that make them viable for biomedical applications [3]. Their particle size can be controlled in the nanometric scale and they can be functionalized with biocompatible molecules to interact with biological entities. Many researchers have been focusing on the nanoscale because magnetic nanoparticles contain a simple magnetic domain and show a superparamagnetic behavior at room temperature, which means that the magnetization $M$ is close to zero in the absence of a magnetic field, but when an external magnetic field is applied, the magnetic moments are aligned with the field [4]. This kind of magnetic response is highly desired in biomedical applications because these materials offer the possibility of being manipulated to a specific body area and target biological entities through an external stimulus. This ability of magnetic nanoparticles has allowed them to be used for labeling and manipulating biomolecules as drugs and genes [5-8]. Drug delivery is the most studied application of the magnetic nanoparticles in order to develop a new therapeutic method that increases the effectiveness of anticancer drug [9]. Magnetic drug targeting (MDT) has also been used to improve localized drug delivery to interstitial tumor targets. MDT involves attaching an antibody to the nanoparticles surface in order to get an antibody-antigen coupling ensuring an efficient and controlled drug release [10]. In order to improve the antibody adherence to the nanoparticles, they are coated with a biocompatible and/or biodegradable material to modify 
their surface. The coated material can be a natural polymer such as chitosan, collagen, folic acid, or a synthetic material like dextran, tetraethyl orthosilicate, poly-lactic-co-glycolic acid, polyethylene glycol, and so forth. These materials provide different functional groups attached to the surface of the nanoparticles as aldehyde (-CHO), hydroxyl $(-\mathrm{OH})$, and amine $\left(-\mathrm{NH}_{2}\right)[9,11-14]$. Biological entities, such as antibodies, are attached to the coated nanoparticles through bonding with these functional groups, and the type of ligand defines the effectiveness of these systems.

5 -Nucleotidase (5-ribonucleotide phosphohydrolase; $5 \mathrm{eNT}$ ) is an intrinsic membrane glycoprotein present as an ectoenzyme in a wide variety of mammalian cells. An increased $5 \mathrm{eNT}$ concentration is a bioindicator of hepatobiliary and osseous disease $[15,16]$. In this study, magnetite nanoparticles coated with antibody against 5eNT were developed and adherence of antibody against $5 \mathrm{eNT}$ was investigated with diverse coated materials. The effectiveness of functional groups such as silanol and amine was determined. A double shell nanoparticle was developed in order to improve the antibody adherence. Increase in the antibody content of the nanoparticles improved the effectiveness of the MDT systems as a result of better antibody-antigen coupling.

\section{Experimental Procedures}

2.1. Synthesis of Magnetite Nanoparticles. Magnetic nanoparticles $\left(\mathrm{Fe}_{3} \mathrm{O}_{4}\right)$ were prepared by coprecipitation with a rapid injection method. The starting material was a mixture of $1.3519 \mathrm{~g}$ of $\mathrm{FeCl}_{3} \cdot 6 \mathrm{H}_{2} \mathrm{O}$ (Sigma Aldrich, CAS no. 10025-771) and $0.6820 \mathrm{~g}$ of $\mathrm{FeSO}_{4} \cdot 7 \mathrm{H}_{2} \mathrm{O}$ in $25 \mathrm{~mL}$ of distilled water. Subsequently, $25 \mathrm{~mL}$ of $\mathrm{NH}_{4} \mathrm{OH}$ was added abruptly in a rapid injection process to increase the $\mathrm{pH}$ value to 12 . A black precipitate was formed; it was washed several times until the supernatant reached a $\mathrm{pH}$ value of 6.5. The precipitate was dried in a vacuum oven at $30 \pm 5^{\circ} \mathrm{C}$ for $24 \mathrm{~h}$.

2.2. Coated Magnetic Nanoparticles. To evaluate the enzymatic adherence to the nanoparticle surface, three different nanoparticles were obtained: magnetite with a silica shell (with hydroxyl group), magnetite with aminosilane shell (with amine group), and magnetite with a double shell silicaaminosilane. For magnetite with a silica shell (MS samples), $1.910 \mathrm{~g}$ of sodium silicate $\left(\mathrm{Na}_{2} \mathrm{SiO}_{3}\right)$ was dissolved in $100 \mathrm{~mL}$ of deionized water in a flask, $0.20 \mathrm{~g}$ of $\mathrm{Fe}_{3} \mathrm{O}_{4}$ nanoparticles was added to this solution and sonicated using Ultra-Turrax for 30 minutes. Further, the temperature of the mixture was increased to $80^{\circ} \mathrm{C}$ and hydrochloric acid was added dropwise until pH 6.0 was attained. The material was then washed several times with deionized water by magnetic decantation. This procedure was repeated twice in order to ensure that the magnetite was coated with silica.

For magnetite with aminosilane shell (MA samples), $1.0 \mathrm{~mL}$ of $\mathrm{N}$-(2-aminoethyl)-3 aminopropyltrimethoxysilane was dissolved in a solution containing $250 \mu \mathrm{L} \mathrm{H} \mathrm{H}_{2} \mathrm{O}$ and $25 \mathrm{~mL}$ of methanol, and then $0.20 \mathrm{~g}$ of magnetite nanoparticles was added. The mixture was exposed to ultrasonic homogenizer for 30 minutes. Subsequently, $15 \mathrm{~mL}$ glycerol was added, and the temperature of the mix was increased to $90^{\circ} \mathrm{C}$ with rapid stirring for $6 \mathrm{~h}$. The product was washed several times with deionized water and methanol and concentrated by magnetic decantation; the material was dried at room temperature. For double shell silica-aminosilane nanoparticles (MSA samples), a similar methodology (as mentioned above) was used with the exception that the starting nanoparticles were precoated with silica.

2.3. Antibody Adherence to Coated Nanoparticles. Two types of antibodies against $5^{\prime}$-nucleotidase were used in order to compare antigen affinity: a commercially purified antiCD73 monoclonal antibody (Ecto- $5^{\prime}$-nucleotidase, 5F/B9, BD Pharmingen) (namely, CD73) and single chain fragment Fv monoclonal antibody obtained by phage display method (namely, ScFv) [16]. $100 \mu \mathrm{L}$ of antibodies solution was incubated in a flask containing $0.02 \mathrm{~g}$ of functionalized magnetic particles for $24 \mathrm{~h}$ at room temperature with slow agitation. The material was washed several times with $1.0 \mathrm{M}, \mathrm{pH} 7.4$ phosphate buffer solution (PBS). Finally, the material was suspended in $100 \mu \mathrm{L}$ of PBS and stored at $4^{\circ} \mathrm{C}$. The adherence of the antibody to functionalized magnetic nanoparticles (FMNPs) was determined by measuring absorbance at $280 \mathrm{~nm}$ in a UV-Vis spectrophotometer (Thermo Scientific Nanodrop 2000).

2.4. $5^{\prime}$-Nucleotidase Enzyme Separation. In order to evaluate the effect of the surface modification on $5^{\prime}$-nucleotidase (5eNT) separation, magnetite with no modification (M), silica-magnetite (MS), silica-aminosilane-magnetite (MSA), silica-amino silane-ScFv antibody-magnetite (MSACF), and silica-aminosilane-anti-CD73 antibody (MSA-CD73) were tested. In the first step, an initial solution of $1.0 \mathrm{M}$ of the $5 \mathrm{eNT}$ (Sigma-Aldrich; CAS no. 9027-73-0) in PBS (Sigma-Aldrich, CAS no. 7447-40-7) pH 7.4, was incubated with $0.02 \mathrm{~g}$ of each material at room temperature for $24 \mathrm{~h}$ in a microcentrifuge tube in a rotator with gentle mixing. After the immobilization step, the magnetically loaded nanosorbents carrying probe enzymes were removed from the medium by applying an external magnetic field. Finally, separation efficiencies were determined by measuring the initial and final enzyme concentrations before and after the separation step using a Bradford colorimetric method at $595 \mathrm{~nm}$ wavelengths.

\subsection{Characterization of Magnetite Nanoparticles. X-ray} diffraction (XRD; PANalytical XRD84) was used to confirm the formation of the crystalline phase of magnetite $\left(\mathrm{Fe}_{3} \mathrm{O}_{4}\right)$. Field emission scanning electron microscopy (FESEM; JEOL 7000F) was used to analyze the morphology and particle size distribution was determined by using Scandium software with SEM images. The superparamagnetic behavior was confirmed by a vibrating sample magnetometer (VSM). Magnetic measurements were performed at room temperature in magnetic field up to $20 \mathrm{kOe}$. The Fourier transform infrared spectra (FTIR; Thermo Scientific Nicolet 6700) was used to confirm the adherence of the polymeric shell to the nanoparticles. Enzyme and antibody adsorption 


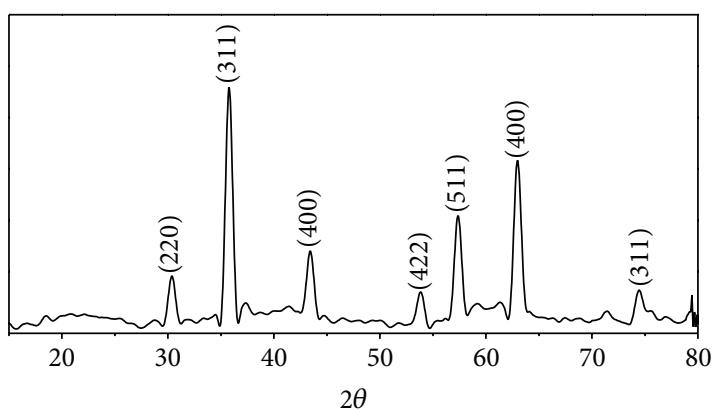

FIGURE 1: X-ray pattern of magnetite nanoparticles.

on magnetite nanoparticles was analyzed in a UV-Vis spectrophotometer at a wavelength of $280 \mathrm{~nm}$.

\section{Results and Discussion}

The XRD patterns of the nanoparticles obtained $(M)$ in this study are shown in Figure 1. The spectra showed six characteristic diffraction peaks of an inverse spinel crystal of the magnetite structure. Average crystallite size was estimated from X-ray pattern by using Scherrer's formula and using the line broadening measurements (FWHM) of the most intense peak. The obtained value was $12.8 \mathrm{~nm}$, which was similar to the particle size values observed by TEM (Figure 2(a)). This suggests that the magnetite nanoparticles are monocrystalline.

TEM image shows that spherical particles with a narrow particle distribution ( $16 \pm 4 \mathrm{~nm}$ ) were obtained, and because of their size and greater reactivity, the nanoparticles form agglomerates between 50 and $80 \mathrm{~nm}$. Figures 2(b) and 2(c) show TEM images of the functionalized nanoparticles with silica shell and double shell silica-aminosilane. The nanoparticles were obtained with silica shell agglomerated with a coating thickness of $2.9 \pm 0.2 \mathrm{~nm}$; however, when double shell silica-aminosilane was obtained, particles distributed between 100-200 nm with polymagnetic cores and the coating thickness increased to $5.8 \pm 0.8 \mathrm{~nm}$.

Hysteresis loops of the magnetite nanoparticles are shown in Figure 3. Magnetite with and without coated material shows a superparamagnetic behavior that is desirable for biomedical applications. Magnetite has saturation magnetization $\left(M_{s}\right)$ of $55.9 \mathrm{emu} / \mathrm{g}$; this value decreases by $14 \%$ when magnetite is coated with a silica shell, $28.6 \%$ with an aminosilane shell, and 23\% with a double shell. The decrease in the magnetization was due to the presence of the coating material. This property indicates the statistical average of the magnetic moments in the direction of the external magnetic field. In this case, there are two materials, but only magnetite nanoparticles are ferromagnetic material and this property is divided by the total mass of the material (magnetite nanoparticles + coated material) [17]. According to Das et al., $40 \mathrm{emu} / \mathrm{g}$ is enough to easily and quickly manipulate the nanoparticles in the presence of an external magnetic field in a body [12]. The superparamagnetic condition is not influenced by agglomeration because each particle has its own magnetic moment; according to Cullity and Graham, this property depends on the particle size [18].

Functionalized magnetite with silica was confirmed by FTIR analysis. Figure 4 shows the characteristic adsorption band at $586 \mathrm{~cm}^{-1}$ due to the $\left(\mathrm{Fe}_{\text {tetra }}-\mathrm{O}\right)$ stretching vibrations of the magnetite. When these particles are coated with silica, the FTIR spectra showed a new band at $1090 \mathrm{~cm}^{-1}$ due to the presence of silanol group [13]; this band was present when the particles were coated with both silica (MS) and double shell silica-aminosilane (MSA). In aminosilane coating samples, bands at 3309 and at $1654 \mathrm{~cm}^{-1}$ were observed, which are attributed to the presence of amine group $\left(-\mathrm{NH}_{2}\right)[14,15]$. The band observed at $2943 \mathrm{~cm}^{-1}$ is due to the stretching of $\mathrm{C}-\mathrm{H}$ of the methyl group $\left(-\mathrm{CH}_{2},-\mathrm{CH}_{3}\right)$. The suggested mechanism of coated particles is shown in Figure 5. In the magnetite-aminosilane shell, the silicon is bonded with the iron through the deprotonation of magnetite. However, when a silica shell is added before the aminosilane groups, the silicon is bonded in the same way with the magnetite and with aminosilane through S-O-S bond, and the resulting band appeared at $804 \mathrm{~cm}^{-1}$. According to these results, magnetite nanoparticles coated with silica have silanol functional group on the surface and magnetite with aminosilane and double shell (silica-aminosilane) has the amine group functional on the nanoparticle surface, and the difference between these two samples lies in the length of the polymeric chain. The surface-modified superparamagnetic nanoparticles are biodegradable and some studies have showed that biodegradation time depends on the kind of coating used in the magnetite nanoparticle. In previous studies, these nanostructures showed $2 \%$ of degradation in a physiological fluid at 18 hours [19]. However, still it is necessary to study the maximum lifetime in a living system.

Figure 6 showed the $5^{\prime}$-nucleotidase immobilization rates using different functionalized magnetite nanoparticles. Clearly, it can be observed that the double shell silicaaminosilane magnetite (MSA) has greater enzymatic adherence than magnetite $(M)$ and silica shell magnetite (MS). This characteristic depends on the type of functional group attached and the length of the polymer chain of the coating material. For this reason, two types of antibodies against $5^{\prime}$-nucleotidase were attached to MSA nanoparticles: antiCD73 monoclonal antibody (MSA-CD73 sample) and single chain fragment Fv monoclonal antibody (MSA-ScFv sample). When an antibody-coated magnetite is used, the immobilization rates were 0.365 and $0.465\left(\mu \mathrm{g}_{5 \mathrm{eNT}} / \mathrm{mg}_{\mathrm{NPs}}\right)$ with antiCD73 and ScFv antibody, respectively. These values were found to be lower than the polymeric-coated nanoparticles values (MSA; $0.5382 \mu \mathrm{g}_{5 \mathrm{eNT}} / \mathrm{mg}_{\mathrm{NPs}}$ ). This can be explained due to the underlying differences in the way in which the enzymes are bound to the material. In the antibodycoated magnetite (MSA-CD73; MSA-ScFv), the immobilization is given by the antibody-antigen binding. The surface of the antibody molecule formed by the juxtaposition of the complementarity-determining regions or CDRs of the heavy and light chains creates the site to which the antibody binds to the amino group of the antigen [20]. Fragments are the minimal portions of an antibody that maintains 

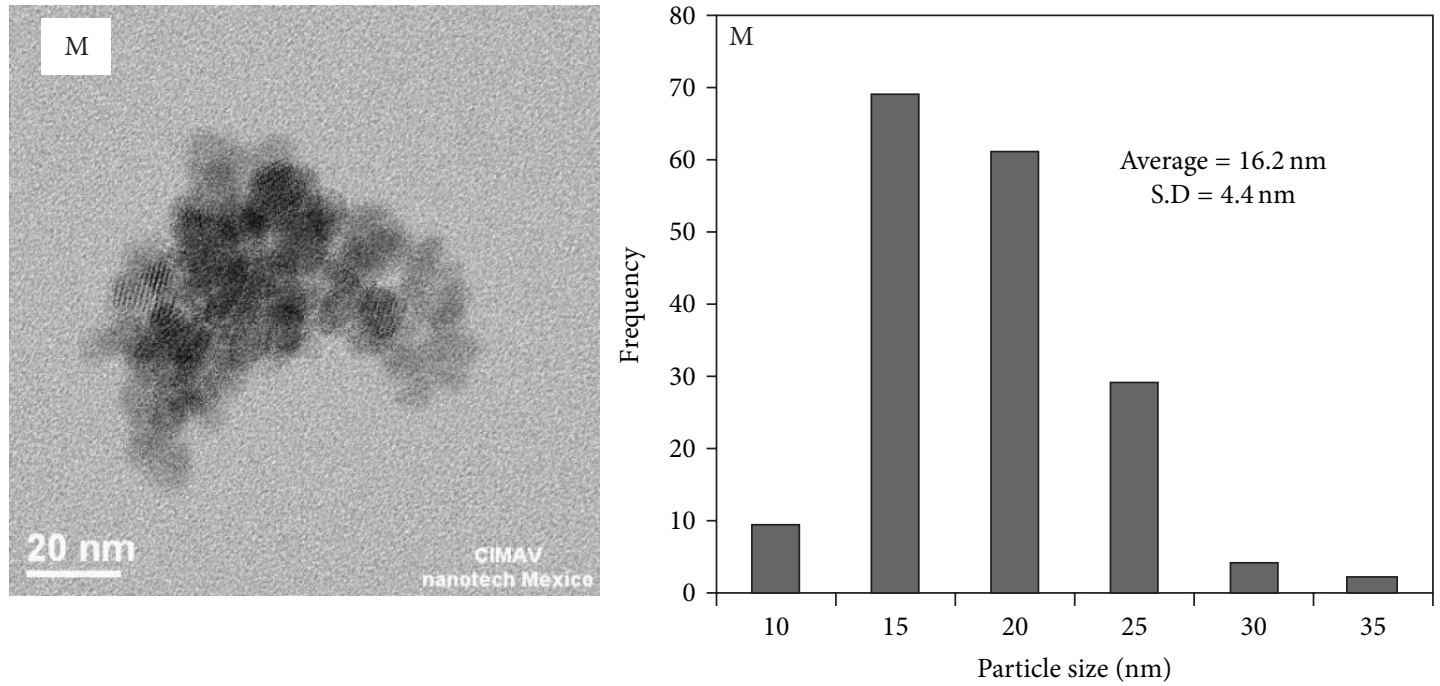

(a)

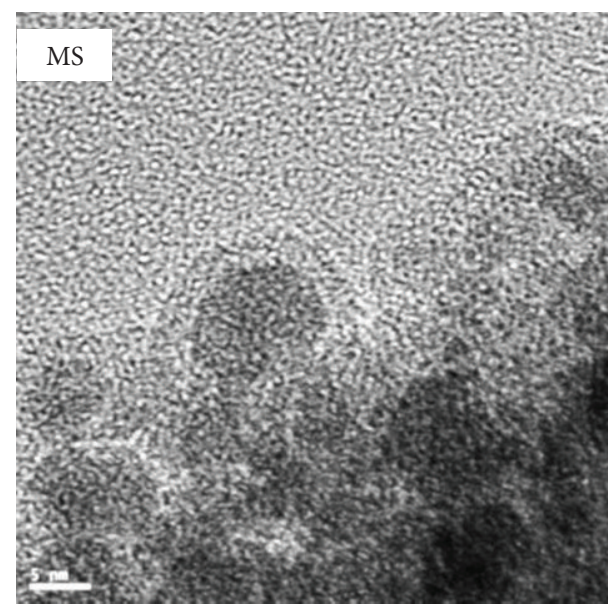

(b)

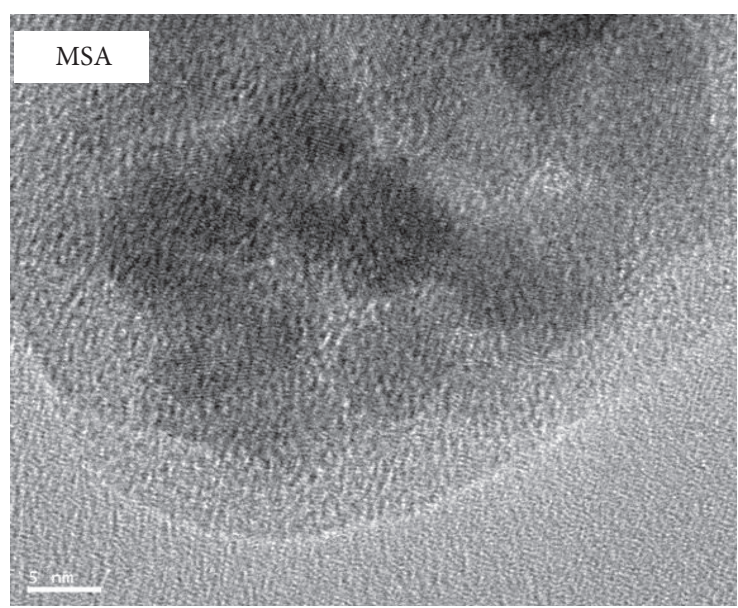

(c)

FIGURE 2: TEM image of (a) magnetite nanoparticles $(M)$ and their particle size distribution, (b) magnetite with silica shell (MS) and (c) double shell silica-aminosilane (MSA).

the antigen-combining site. Increased immobilization using fragments may be due to the small size. Takashi demonstrated that antibody fragments had a better distribution in the tumor, penetrating in less time than complete antibodies [21].

The nanoparticles containing attached antibodies (MSAScFv or MSA-CD73) bind to the enzyme through antibodyantigen coupling. Since the antibodies are covalently coupled to antigen, the resulting bond is stronger and more selective [22], and hence, the antibody-attached magnetite nanoparticles showed higher bioselectivity.

In the case of polymeric coated magnetite, enzyme binds to the external layer by adsorption mechanism. Intermolecular forces, surface, hydrophobicity, and ion electrostatic interaction alter the protein adsorption [23]. In these nanoparticles, the enzyme is accumulated to the surface forming a layer onto functionalized nanoparticles, so differences in the surface of the nanoparticles make the difference in protein adsorption. Magnetite nanoparticles coated with silica have silanol functional group on the surface and magnetite with aminosilane and double shell (silica-aminosilane) has the amine group functional on the nanoparticle surface. The difference in electrostatic interaction makes MSA, with an amine group, more affinity to the protein. Another aspect that increases the immobilization is the difference in the length of the polymeric chain; MSA has the largest chain according to the suggested mechanism of coated magnetite nanoparticles (Figure 5).

Figure 7 shows the ScFv antibody interaction with different enzymes, bovine serum albumin (BSA), ovalbumin (OVA), and a negative control (CN; without enzyme). The results showed that there was no interaction in the negative control because of the absence of enzymes. The immobilization of $5^{\prime}$-nucleotidase (5eNT) was better than the immobilization of other enzymes due to the antibody-antigen 


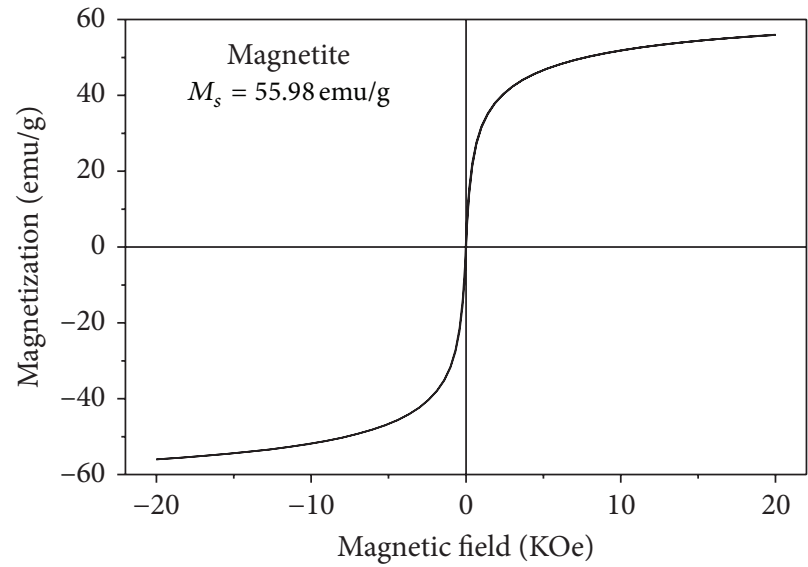

(a)

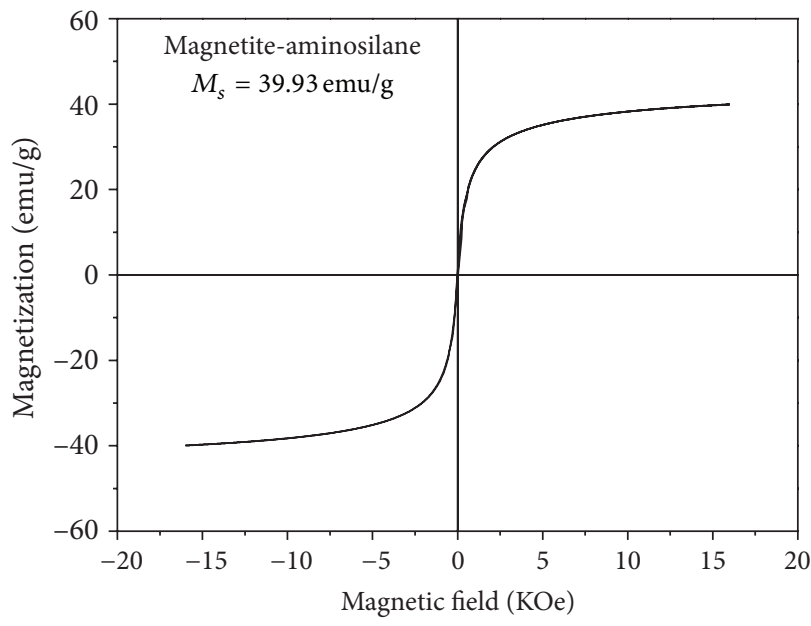

(c)

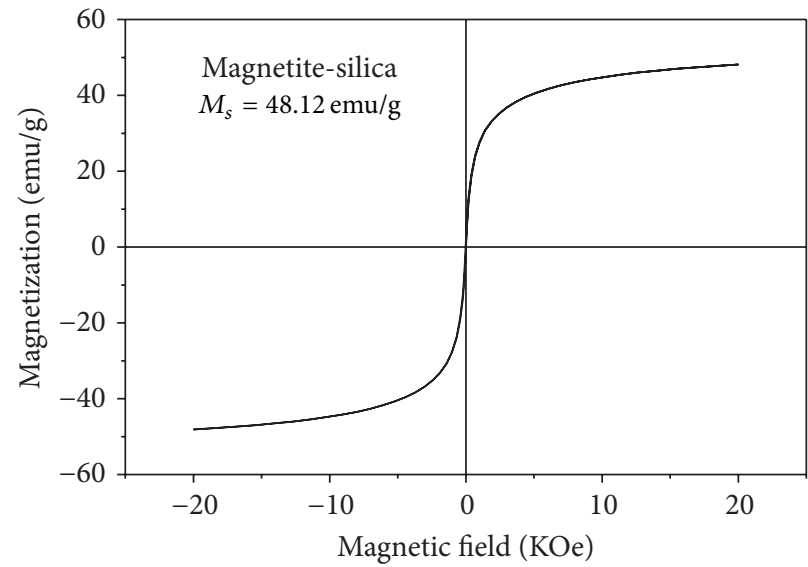

(b)

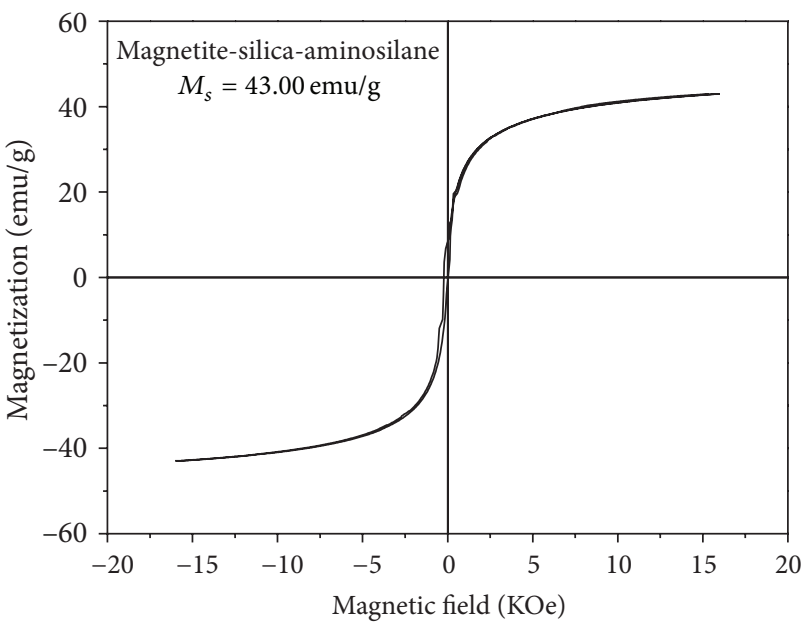

(d)

FIGURE 3: Hysteresis loops of magnetite, magnetite with silica shell, magnetite with aminosilane shell, and double shell silica-aminosilane magnetite.

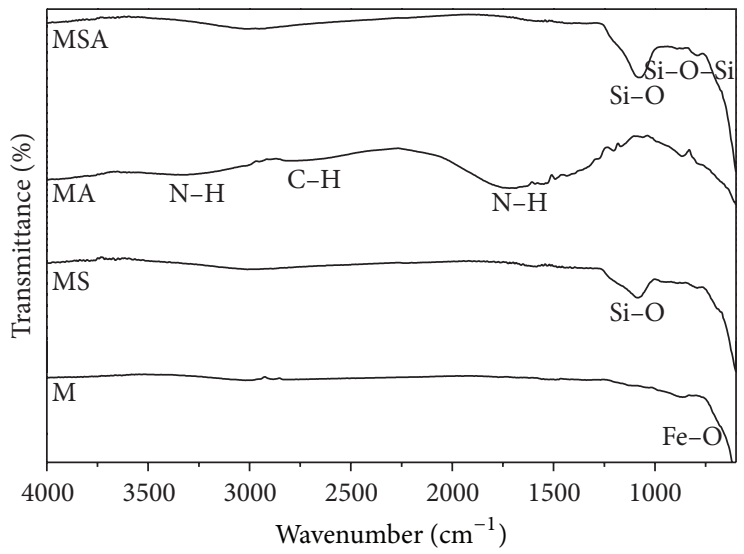

FIGURE 4: FTIR spectra of magnetite (M), magnetite with silica shell (MS), magnetite with aminosilane shell (MA), and double shell silicaaminosilane (MSA) nanoparticles. 


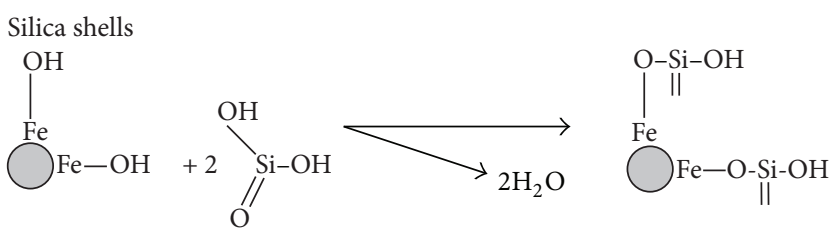

Aminosilane shells

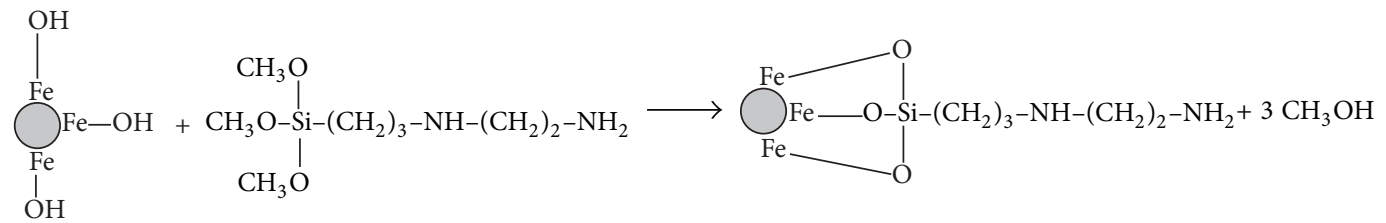

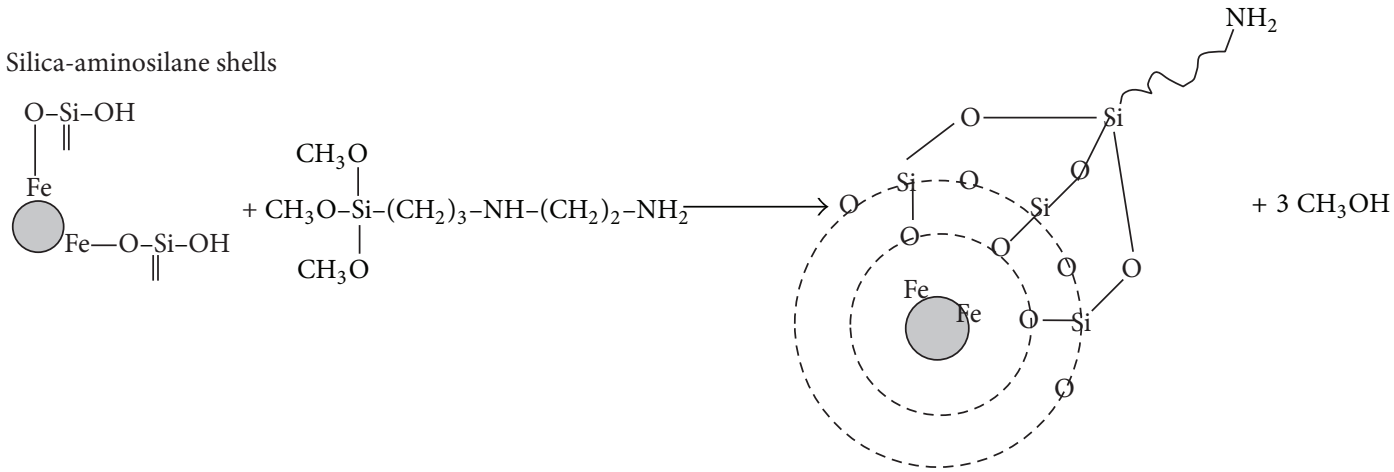

FIGURE 5: Suggested mechanism of coated magnetite nanoparticles.

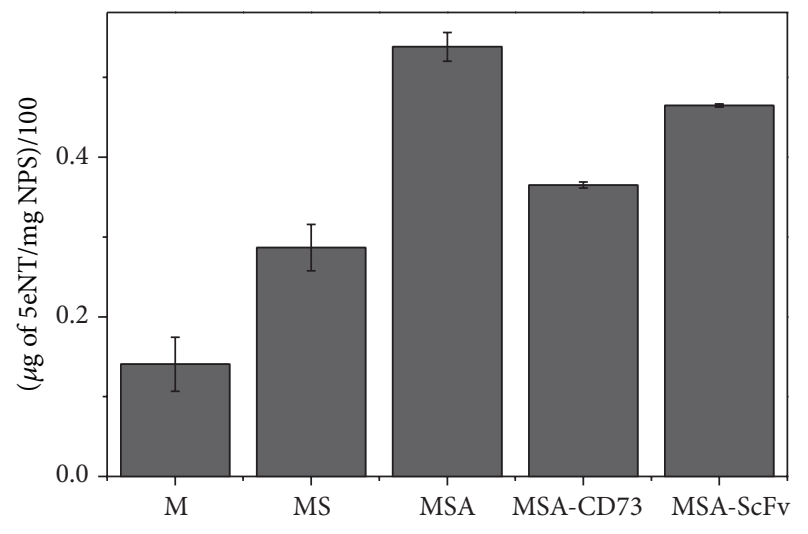

FIGURE 6: $5^{\prime}$-Nucleotidase immobilization rates in different functionalized magnetite nanoparticles.

interaction. Therefore, the use of antibodies onto functionalized nanoparticles resulted in the greater selectivity during the immobilization of enzymes.

\section{Conclusions}

Antibody-coated magnetite nanoparticles for immobilization of $5^{\prime}$-nucleotidase were developed. The enzyme immobilization grade depends on the type of functional group used and the length of the polymer chain of the coating material. In this study, amine functional group showed higher affinity than

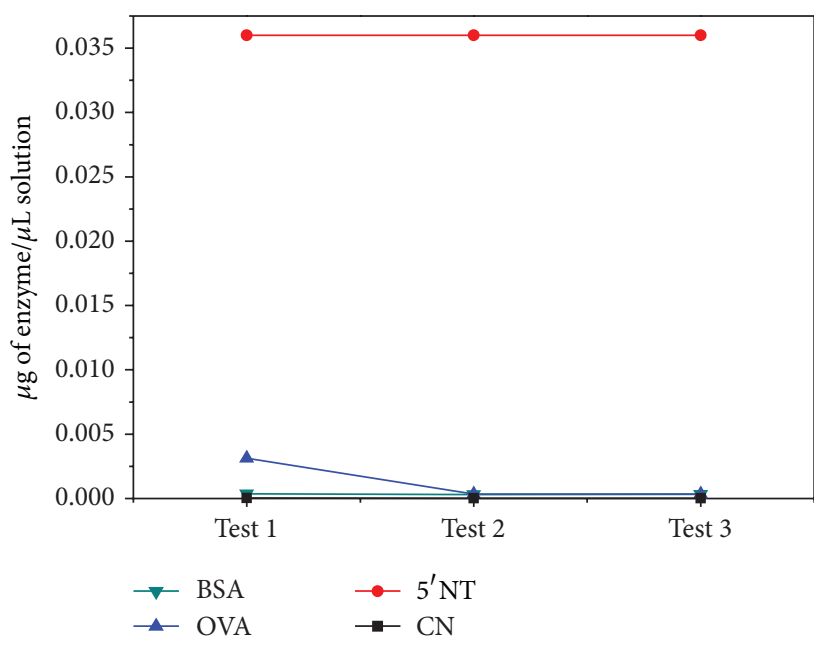

Figure 7: Affinity of the ScFv antibody with the $5^{\prime}$-nucleotida.

silanol functional group. The adherence of $5^{\prime}$-nucleotidase enzyme improved on increasing the polymeric chain length of the coating material. This shows that the magnetite nanoparticles with a double shell (silica-aminosilane) are more sensitive than magnetite with a single shell in the detection of biomarkers, but when antibody-coated nanoparticles are used, the enzyme immobilization becomes more selective. 


\section{Conflict of Interests}

The authors declare that there is no conflict of interests regarding the publication of this paper.

\section{References}

[1] V. Varadan, L. Chen, and J. Sie, Nanomedicine: Design and Applications of Magnetic Nanomaterials, Nanosensors and Nanosystems, Wiley-VCH, Weinheim, Germany, 2008.

[2] G. A. O. Jinhao, G. U. Hongwei, and X. U. Bing, "Multifunctional magnetic nanoparticles: design, synthesis, and biomedical applications," Accounts of Chemical Research, vol. 42, no. 8, pp. 1097-1107, 2009.

[3] Q. A. Pankhurst, J. Connolly, S. K. Jones, and J. Dobson, "Applications of magnetic nanoparticles in biomedicine," Journal of Physics D, vol. 36, no. 13, pp. R167-R181, 2003.

[4] R. Cornell and U. Schwertmann, The Iron Oxides: Structure, Properties, Reactions, Occurrences and Uses, Wiley-VCH, Weinheim, Germany, 2003.

[5] D.-M. Fan, H.-R. Shi, Z.-M. Chen, Q.-H. Wu, H.-N. Liu, and R.T. Zhang, "Early detection of ovarian carcinoma by proteome rofiling based on magnetic bead separation and atrix-assisted laser desorption/ionization time of flight mass spectrometry," African Journal of Microbiology Research, vol. 4, no. 10, pp. 940951, 2010.

[6] A. Figuerola, R. Di Corato, L. Manna, and T. Pellegrino, "From iron oxide nanoparticles towards advanced iron-based inorganic materials designed for biomedical applications," Pharmacological Research, vol. 62, no. 2, pp. 126-143, 2010.

[7] A. Jordan, R. Scholz, P. Wust, H. Fähling, and R. Felix, "Magnetic fluid hyperthermia (MFH): cancer treatment with AC magnetic field induced excitation of biocompatible superparamagnetic nanoparticles," Journal of Magnetism and Magnetic Materials, vol. 201, no. 1-3, pp. 413-419, 1999.

[8] K. Eunkyung, L. Sanghwa, J. Aram et al., "A single-molecule dissection of ligand binding to a protein with intrinsic dynamics," Nature Chemical Biology, vol. 9, pp. 313-318, 2013.

[9] J.-H. Park, K.-H. Im, S.-H. Lee et al., "Preparation and characterization of magnetic chitosan particles for hyperthermia application," Journal of Magnetism and Magnetic Materials, vol. 293, no. 1, pp. 328-333, 2005.

[10] S. Dandamudi and R. B. Campbell, "The drug loading, cytotoxicty and tumor vascular targeting characteristics of magnetite in magnetic drug targeting," Biomaterials, vol. 28, no. 31, pp. 46734683, 2007.

[11] R. T. Reza, C. M. Pérez, A. M. Martínez, D. B. Baques, and P. García-Casillas, "Study of the particle size effect on the magnetic separation of bovine serum albumin (BSA)," Sensor Letters, vol. 8, no. 3, pp. 476-481, 2010.

[12] M. Das, D. Mishra, T. K. Maiti, A. Basak, and P. Pramanik, "Bio-functionalization of magnetite nanoparticles using an aminophosphonic acid coupling agent: new, ultradispersed, iron-oxide folate nanoconjugates for cancer-specific targeting," Nanotechnology, vol. 41, no. 19, Article ID 415101, 2008.

[13] A. del Campo, T. Sena, J. Lellouchec, and J. Bruce, "Multifunctional magnetite and silica-magnetite nanoparticles: synthesis, surface activation and applications in life sciences," Journal of Magnetism and Magnetic Materials, vol. 293, no. 1, pp. 33-40, 2005.
[14] H. Zimmermann, “5'-Nucleotidase: molecular structure and functional aspects," Biochemical Journal, vol. 285, part 2, pp. 345-365, 1992.

[15] F. Pagani and M. Panteghini, " $5 /$-Nucleotidase in the detection of increased activity of the liver form of alkaline phosphatase in serum," Clinical Chemistry, vol. 47, no. 11, pp. 2046-2048, 2001.

[16] A. Martinez Martinez, C. Flores-Flores, F. J. Campo, E. MuñozDelgado, C. Fini, and C. J. Vidadl, "Biochemical properties of $5^{\prime}$-nucleotidase from mouse skeletal muscle," Biochimica et Biophysica Acta: Protein Structure and Molecular Enzymology, vol. 1386, no. 1, pp. 16-28, 1998.

[17] B. Buschow, Physics of Magnetism and Magnetic Materials, Kluwer Academic, Germany, 2004

[18] B. D. Cullity and C. D. Graham, Introduction to Magnetic Materials, John Wiley \& Sons, New York, NY, USA, 2009.

[19] K. I. Baca Ramos, C. A. Martinez Perez, C. A. R. González et al., Stability of Functionalized Magnetic Particles in a Physiologic Fluid, vol. 1 of NSTI-Nanotech, 2012.

[20] C. A. Janeway, P. Travers, and M. Walport, Immunobiology: The Immune System in Health and Disease. Part II. The Recognition of Antigen, Garland Science, New York, NY, USA, 2001.

[21] T. Yokota, D. E. Milenic, M. Whitlow, and J. Schlom, "Rapid tumor penetration of a single-chain Fv and comparison with other immunoglobulin forms," Cancer Research, vol. 52, no. 12, pp. 3402-3408, 1992.

[22] S. Nandimi, Immunology: Introductory Textbook, New Age International, USA, 2005.

[23] I. Lundström, "Models of protein adsorption on solid surfaces," in Surfactants, Adsorption, Surface Spectroscopy and Disperse Systems, pp. 76-82, 1985. 

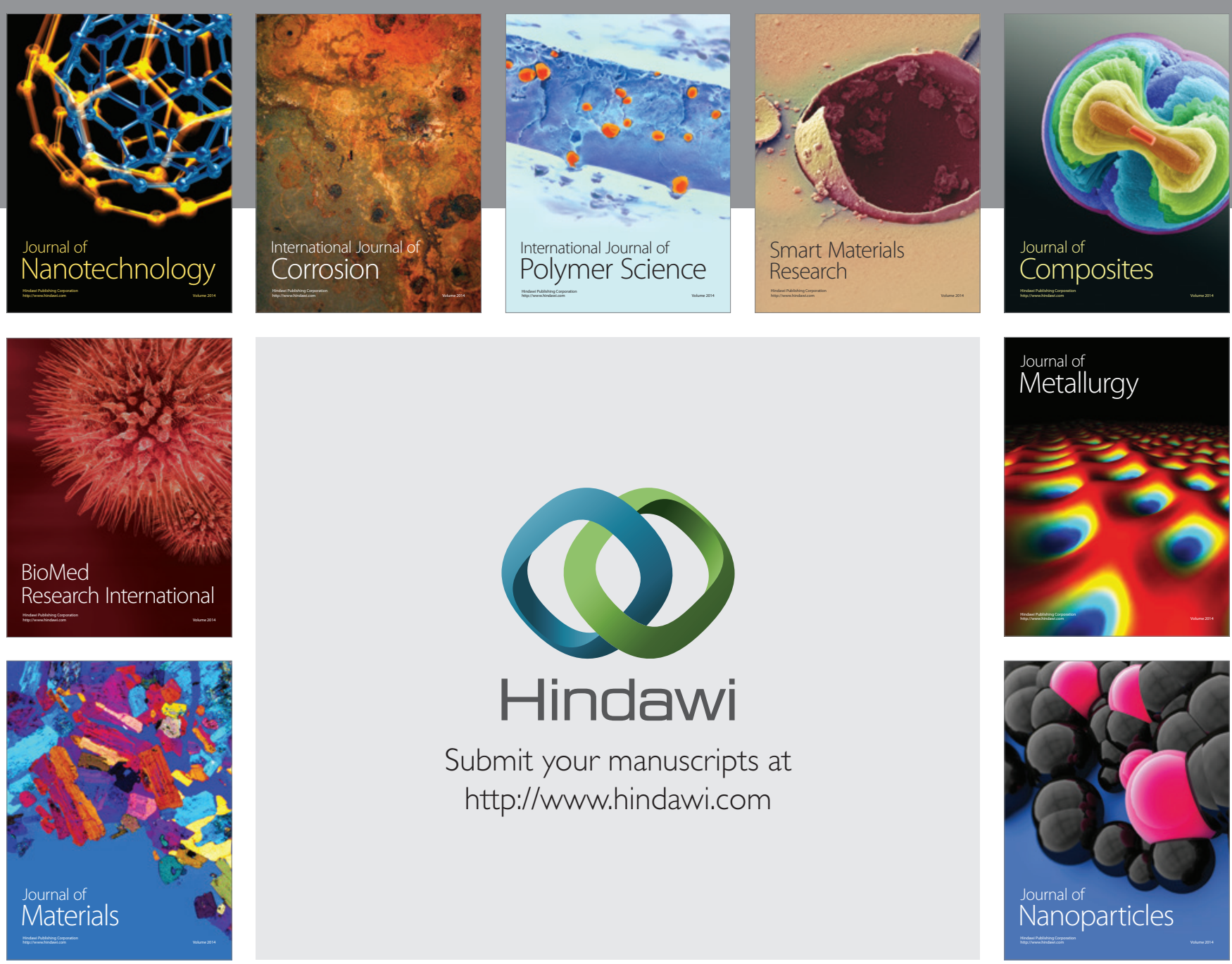

Submit your manuscripts at http://www.hindawi.com
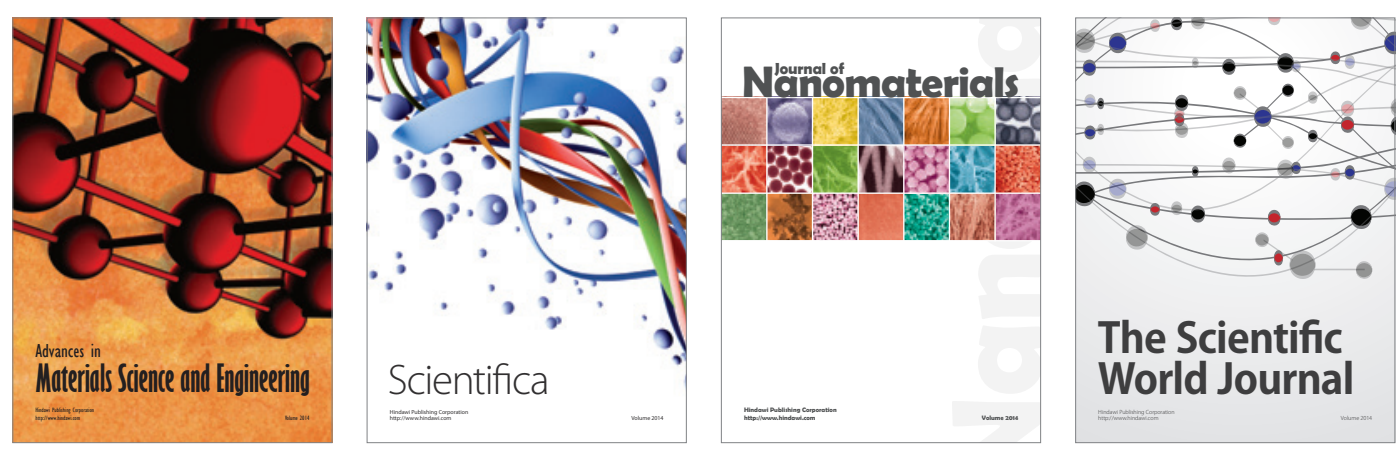

\section{The Scientific World Journal}
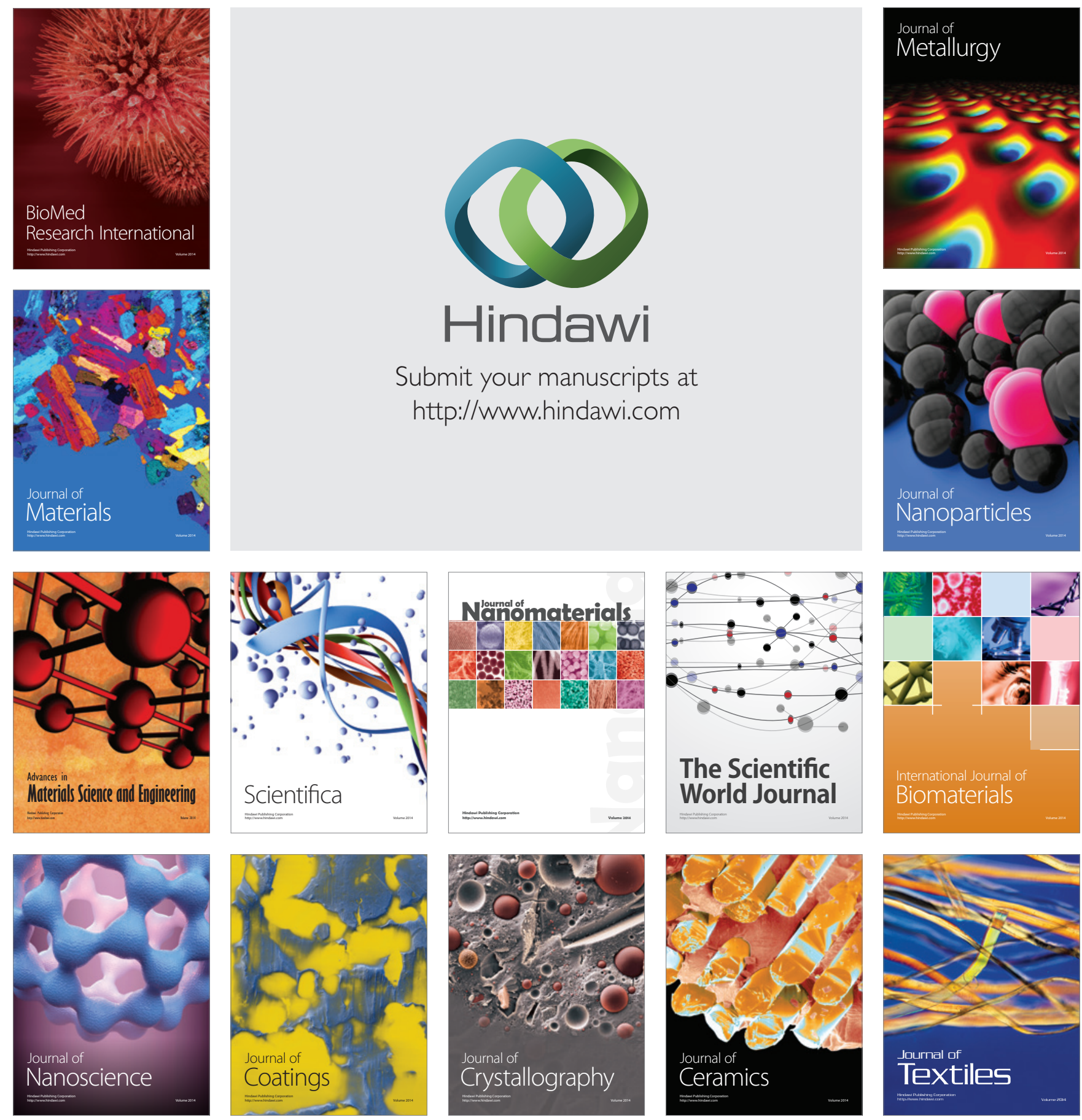